\title{
REFLEXÃO SOBRE ORTODOXIA ECONÔMICA E ESTADO DE EXCEÇÃO ENQUANTO AMEAÇAS AOS DIREITOS FUNDAMENTAIS
}

\author{
REFLECTION UPON ECONOMIC ORTHODOXY AND STATE OF EXCEPTION \\ AS THREATS TO FUNDAMENTAL RIGHTS
}

\author{
${ }^{1}$ Matheus Fernando de Arruda e Silva \\ ${ }^{2}$ Mirta Gladys Lerena Manzo de Misailidis
}

\section{RESUMO}

O artigo consiste em uma reflexão de caráter teórico e de orientação metodológica sociológica jurídica para demonstrar que, dado uma situação de emergência econômica, os direitos fundamentais dos cidadãos passam a ficar fragilizados pela aplicação do receituário econômico ortodoxo neoliberal. Assim, emerge o confronto de um capitalismo ortodoxo versus um capitalismo humanista. Nessa reflexão consideramos a constituição de um estado de exceção de fato, não limitado às previsões constitucionais de estado de defesa e de sítio, resultado da aplicação de uma ideologia dos governos que priorizam a economia em detrimento do social.

Palavras-chave: Capitalismo; Direitos Fundamentais; Estado de exceção; Neoliberalismo; Ortodoxia

\begin{abstract}
The article consists in a reflection of theoretical character and socio-legal guidance to demonstrate that, in a situation of economic emergency, the citizens' fundamental rights become weakened by the application of economical recipes of neoliberal character. Therefore, emerges the confrontation between an orthodox capitalism versus a humanitarian capitalism. In our reflection we consider the hypothesis of the constitution of a state of exception factbased, not limited to the constitutional provision of state of defense and siege, that is resulted from the application of an ideology utilized by the governments that prioritize the economy over the well-being of their citizens.
\end{abstract}

Keywords: Capitalism; Fundamental rights; Neoliberalism; Orthodoxy; State of exception

\footnotetext{
${ }_{1}$ Mestrando do Programa de Pós-graduação Stricto Sensu em Direito pela Universidade Metodista de Piracicaba (UNIMEP), São paulo, Brasil. Bolsista CAPES/PROSUP. Bacharel em Relações Internacionais pela Faculdades de Campinas (FACAMP), São Paulo, Brasil Email: mfasilva@icloud.com

${ }^{2}$ Doutora em Direito das Relações Sociais pela Pontifícia Universidade Católica de São Paulo (PUC-SP), São Paulo, Brasil. Professora do Programa de Pós-graduação Stricto Sensu em Direito da Universidade Metodista de Piracicaba (UNIMEP), São paulo, Brasil. Email: lerena@uol.com.br
} 


\section{INTRODUÇÃO}

Atualmente os países, independentemente de seu nível de desenvolvimento, enfrentam duas situações paradoxais de princípios antagônicos e excludentes sobre as quais repousa a democracia capitalista: o acúmulo do capital, que é a própria finalidade do capitalismo, e as demandas sociais, que são a essência do Estado Democrático de Direito. Nesse paradoxo, característica de todas as democracias capitalistas, como salienta Boron (2001, p. 231), está presente a discussão sobre a crise das democracias tanto nos países do capitalismo avançado como periférico.

Com relação a essa lógica da democracia capitalista, afirma Herrera Flores (2009, p. 104) que a pós-modernidade cobre os olhos da humanidade com um véu de alienação que lhe permite assistir o atual momento histórico, fascinado com o mundo das modas, das viagens turísticas e das programações televisivas sem questionar as devastações das florestas, a fome, a vulnerabilidade da vida humana, as vítimas das epidemias que assolam os países periféricos da ordem econômica mundial, fruto dos acordos com a Organização Mundial do Comércio, que impede a venda de remédios genéricos das empresas farmacêuticas transnacionais em benefício dos direitos de patentes, provocando um verdadeiro genocídio nas populações pobres e obstaculizando as políticas sociais de países democráticos.

Não obstante, cabe observar que o neoliberalismo, fruto do pensamento econômico ortodoxo, intensificou a exploração do capitalismo até seu limite e com isso provocou a crise econômica mundial de 2008, sendo que é possível afirmar que seus efeitos são sentidos até os dias de hoje. Recentemente exibidos nos cinemas do país, o filme de 2015 "A Grande Aposta”, de maneira didática, demonstra a ausência de ética nas transações do sistema financeiro mundial e como o mesmo provocou o desemprego em massa e atingiu os cidadãos subalternos do sistema, a classe pobre, dos Estados Unidos da América.

O fio condutor desse artigo, que segue uma orientação metodológica de eixo sociológico-jurídico, é uma reflexão do capitalismo neoliberal e estado democrático de direito. A lógica do neoliberalismo consiste na competição, a segmentação, a seletividade, dentro de uma lógica racional de equilíbrio dos mercados, ao passo que a democracia se orienta a conferir a seus membros a condição de cidadão, que só pode ser alcançada a partir do pleno exercício dos direitos fundamentais. Nesse sentido, conforme aponta Boron (2001, p. 
181), a lógica da democracia é um jogo de somas positivas, e a do mercado de somas que se anulam, pois, o lucro do capitalismo é a insuficiência do salário ${ }^{3}$.

Estamos nesse momento histórico (final do primeiro semestre de 2016) diante de movimentos sociais, no Brasil e no mundo, que convergem na ideia da garantia de direitos e do exercício da cidadania sem os tradicionais intermediadores do campo político: os partidos políticos. Do outro lado do Oceano Atlântico, o movimento Nuit Débout ocupa desde 31 de março as praças na maioria das cidades francesas e já encontrou adesão em cidades da Europa e do mundo, vez que o que era um protesto contra a redução de direitos sociais se tornou questionamento do exercício da política em geral.

Em ambos os casos, esses movimentos estão brotando em meio a uma crise de Estado. Na França, o movimento ocorre em meio ao recrudescimento da política de segurança diante dos recentes ataques terroristas em Paris. Já no Brasil há uma crise de governabilidade sem precedentes que pôs em xeque não somente o poder executivo, mas também expôs a precariedade do poder legislativo e a dificuldade do poder judiciário de se posicionar diante das questões jurídicas suscitadas pela crise. Assim, o que une atualmente a situação política da França e do Brasil é aquilo que Giorgio Agamben (2004, p. 18) analisa como estado de exceção, uma crônica distância entre o direito e a vida que, em decorrência da globalização financeira, tende a se agravar.

Diante do exposto, nossa reflexão tem como principal objetivo demonstrar que vivemos em uma espécie de estado de exceção de fato, na qual os cidadãos, especialmente aqueles das classes menos favorecidas, arquem com a supressão de seus direitos fundamentais em decorrência da lógica econômica do capitalismo ortodoxo neoliberal.

Antes de avançarmos em nossas reflexões, cabe uma breve consideração sobre a estrutura desse trabalho. Em primeiro lugar buscaremos definir conceitos básicos para permitir ao leitor se familiarizar com o tema, especificamente: estado de defesa, estado de exceção e estado de sítio. Nossa intenção não é a de promover um esgotamento teórico, mas uma base de entendimento comum que dê sustentação ao nosso objetivo principal. Uma vez compreendidos os conceitos supracitados, partiremos para uma abordagem sobre a influência do pensamento econômico ortodoxo e a construção teórica dessa vertente. E, por fim, valendo-se da base criada nas duas seções anteriores, estabeleceremos nossas reflexões sobre

\footnotetext{
${ }^{3}$ Para melhor compreensão dessa passagem, sugerimos ao leitor que busque na clássica obra de Karl Marx "O Capital”, em seu volume I, o entendimento acerca do processo de extração da mais valia e a formulação do lucro. Cf. Marx (2013).
} 
o impacto da ortodoxia econômica frente aos direitos fundamentais ou, em outras palavras, a derrubada do capitalismo humanista pela lógica perversa da ortodoxia econômica neoliberal.

2 DESMITIFICAÇÃ̃o DE CONCEITOS: estado de defesa, estado de exceção e estado de sítio

Para a compreensão desse artigo, é necessário que o leitor se familiarize com alguns termos: estado de defesa, estado de exceção, e estado de sítio.

Na Constituição Brasileira de 1988 (BRASIL, 1988), por exemplo, encontramos no Título V ("Da defesa do Estado e das Instituições Democráticas"), Capítulo I (Do Estado de defesa e do Estado de Sítio), os termos estado de defesa (Seção I) e estado de sítio (Seção II), dispostos nos artigos 136 até 139 e com as disposições gerais nos artigos 140 e 141 . No primeiro caso, estado de defesa, de forma expressa no caput do art. 136 temos que o objetivo desse instituto é "para preservar ou prontamente restabelecer, em locais restritos e determinados, a ordem pública ou a paz social ameaçada por grave e iminente instabilidade institucional ou atingidas por calamidades de grandes proporções na natureza”. Já o segundo o caso, estado de sítio, seria aplicado conforme as situações previstas nos incisos I e II do art. 137, respectivamente "comoção grave de repercussão nacional ou ocorrência de fatos que comprovem a ineficácia de medida tomada durante o estado de defesa" e "declaração de estado de guerra ou resposta a agressão armada estrangeira".

Considerando a redação do texto constitucional, desde já podemos afirmar que ambos os casos tratam de uma situação que foge da normalidade e é necessariamente uma ameaça à preservação do Estado e que, justamente por esse motivo, tais medidas são invocadas com o propósito de se voltar à situação de normalidade. Contudo, cabe observar um elemento que os distingue: a restrição ainda maior dos direitos fundamentais. Em ambos o direito de reunião (ainda que no seio das associações legais), sigilo de correspondência, comunicação telegráfica e telefônica são restritos, mas na hipótese de estado de sítio é ainda admitida obrigação de permanência em localidade determinada (art. 139, I), detenção em edifício não destinado a acusados ou condenados por crimes comuns (art. 139, II), restrições relativas à prestação de informações, liberdade de imprensa, radiofusão e televisão (art. 139, III), busca e apreensão em domicilio (art. 139, V), intervenção nas empresas de serviços públicos (art. 139, VI) e requisição de bens (art. 139, VII). 
Diante disso, podemos afirmar que, de forma expressa pelo texto constitucional, os seguintes direitos fundamentais seriam então restritos: livre manifestação de pensamento (art. $5^{\circ}$, IV), livre comunicação (art. $5^{\circ}$, IX), a inviolabilidade do lar (art. $\left.5^{\circ}, \mathrm{XI}\right)$, inviolabilidade de correspondência e comunicações telegráficas, de dados e telefônicas (art. $5^{\circ}, \mathrm{XII}$ ), liberdade de reunião (art. $5^{\circ}, \mathrm{XVI}$ ), liberdade de associação (art. $\left.5^{\circ}, \mathrm{XVII}\right)$, direito de propriedade (art. $\left.5^{\circ}, \mathrm{XXII}\right)$, etc. Cabe, todavia, um adendo para observar que a liberdade de locomoção em todo o território nacional (art. $5^{\circ}, \mathrm{XV}$ ) é apenas admitida de forma plena em tempos de paz, ou seja, é um direito fundamental relativo já que se a situação não se der em tempos de paz não há de se falar em liberdade de locomoção. Porém, é ainda de se ter em vista que além dos direitos fundamentais, as garantias fundamentais também podem ser alvos de restrições no caso do estado de sítio, a exemplo do disposto de forma expressa no caput do art. 138.

Felizmente, mesmo nas situações de estado de defesa e de sítio, a Constituição de 1988 estabelece restrições para que não seja algo de duração ad eterna e ainda limites com relação a restrição dos direitos. Isso porque tais medidas irão ocorrer em um ambiente em que o Estado, em que pese estar diante de uma situação de anormalidade, continua sendo como Democrático de Direito e como tal trata essas restrições como excepcionais.

De todo modo, o que parece certo de se afirmar é que independentemente de se tratar de estado de defesa ou de sítio, parecem convergir para uma situação de excepcionalidade sendo essa excepcionalidade a supressão dos direitos fundamentais. Assim, se a normalidade é o exercício e gozo plenos dos direitos fundamentais, o estado de exceção seria a hipótese em que seria admitido a sua não ocorrência e, por conta disso, o termo estado de exceção compreenderia em si tanto o estado de defesa como o de sítio.

O estatuto do estado de guerra e estado de sítio não é algo novo. Se retomarmos a história, veremos que o estatuto do estado de sitio tem sua origem no decreto de 8 de julho de 1791 da Assembleia Constituinte francesa que, conforme explica Agambem (2004, p. 16) "distinguia entre état de paix, em que a autoridade militar e autoridade civil agem cada uma em sua própria esfera; état de guerre, em que a autoridade civil deve agir em consonância com a autoridade militar; état de siège", sendo que nesse último caso "todas as funções de que a autoridade civil é investida para a manutenção da ordem e da polícia internas passam para o comando militar, que as exerce sob sua exclusiva responsabilidade" (REINACH, 1886, p. 109 apud AGAMBEN, 2004, p. 16). No entanto com o decorrer da história o estado de sítio passará a ser distanciar cada vez mais da situação de guerra "para ser usado, em seguida, 
como medida extraordinária de polícia em casos de desordens e sediações internas, passando, assim, de efetivo ou militar a fictício ou político" (AGAMBEN, 2004, p. 16).

O problema do estado de exceção é quando ele deixa de ser de caráter temporário e se torna permanente já que o que era para ser exceção se torna realidade por tempo indeterminado. Não obstante, já que estamos no período que compreende os 70 anos dos julgamentos ocorridos no "Tribunal de Nuremberg", retomar o passado não tão distante pode nos propiciar valiosas lições. Se no Direito podemos considerar a Constituição de Weimar um marco em termos de direitos fundamentais, de igual modo o Verordnung des Reichspräsidenten zum Schutz von Volk und Staat (também conhecido apenas como Reichstagsbrandverordnung) ou Decreto do Presidente do Reich para a Proteção do povo e do Estado (tradução livre), de 28 de fevereiro de 1933 (ALEMANHA, 1933), também o seria enquanto marco do estado de exceção já que a partir dele ocorreu a supressão dos direitos individuais garantidos na Constituição e que propiciaram o regime totalitário na Alemanha de Hitler por 12 anos ou seja, o que era para ser temporário passou a ser permanente por mais de uma década (Cf. PAULANI, 2006).

Diante dessas ponderações, outro elemento que merece a devida preocupação é a questão da temporariedade. Sendo a exceção de caráter excepcional, parece lógico que ela também é temporária e, em decorrência disso, o que cabe questionar é a duração de sua temporariedade. Quanto tempo deve durar um estado de exceção? No caso da Constituição brasileira, em caso de estado de defesa, conforme o disposto no art. $136, \S 2^{\circ}$ "O tempo de duração do estado de defesa não será superior a trinta dias, podendo ser prorrogado uma vez, por igual período, se persistirem as razões que justificaram a sua decretação" e, para o estado de sítio, conforme art. 138, $\S 1^{\circ}$ "O estado de sítio, no caso do art. 137, I, não poderá ser decretado por mais de trinta dias, nem prorrogado, de cada vez, por prazo superior; no do inciso II, poderá ser decretado por todo o tempo que perdurar a guerra ou a agressão armada estrangeira". A redação da nossa Carta Magna parece sensata: em que pese haver uma possibilidade de prorrogação de 30 dias no caso do estado de defesa e na hipótese do art. 137, I. (art. $136, \S 2^{\circ}$ e art. $138, \S 1^{\circ}$ ), bem como tempo indeterminado em caso de estado de guerra (afinal não se sabe por quanto tempo um possível conflito bélico irá durar), a questão não é tão simples como parece.

Nesse artigo entendemos que o estado de exceção não se limita às hipóteses constitucionais previstas nas constituições dos Estados Democráticos de Direito, a exemplo do disposto na nossa Constituição de 1988 (estado de defesa e estado de sítio). Em outras 
palavras, não entendemos o estado de exceção apenas como fruto de uma declaração formal, mas como um fenômeno que, por vezes, ocorre dentro de ambientes em que o Estado poderia ser considerado como sendo Democrático de Direito. É nesse sentido que a preocupação com a duração do estado de exceção merece importância.

Ao assumirmos que o estado de exceção não se limita às hipóteses legais de nossa Constituição, mas atua como mecanismo de supressão de direitos fundamentais, entendemos também que o fato dele ser temporário já é, por si só, perigoso. Decretar o estado de exceção é tornar legal aquilo que naturalmente não o é. Como não é possível determinar a duração de tal estado de exceção, é certo então afirmar que o mesmo é permanente.

Já que definir com precisão a duração não é uma tarefa fácil, temos então que ter em mente aquilo que a irá motivar. O estado de exceção, e isso também se aplica no nosso texto constitucional de estado de sítio, está necessariamente atrelado ao grau da ameaça que se constitui enquanto espécie de emergência. $\mathrm{O}$ fato de ser uma grave ameaça, uma emergência, o que determinará o tempo e o modo de atuação da exceção que, a princípio, é indeterminado.

Na nossa sociedade contemporânea podemos nos deparar com os mais diversos tipos de emergências, e todas suscetíveis a uma conflagração de estado de exceção. De tal modo, o que nos preocupa nesse artigo são as emergências de natureza política e econômica porque, nesse exato momento histórico, o Brasil se encontra tanto em situação de crise política como econômica.

Quando temos a conflagração da emergência, passamos então a ter uma motivação para superá-la, afinal tudo o que não se deseja é perpetuar essa condição. Ocorre então que o problema, e objeto de crítica, é com relação ao receituário que se dará para combater essa emergência. No caso específico da emergência econômica, temos no Brasil dois grandes exemplos de seus efeitos que repercutiram em âmbito político e no do direito: os impeachments do Presidente Fernando Collor de Mello e da Presidente Dilma Rousseff ${ }^{4}$. Em ambos os casos o que se têm são presidentes que, a priori, foram democraticamente eleitos, mas que não souberam lidar com a situação de emergência econômica.

A perversidade da emergência econômica se constitui enquanto uma ameaça direta à democracia. Ao se assumir que quaisquer medidas são válidas, que o esforço deve ser dividido entre todos da sociedade, o que se está fazendo é a condenação de toda uma nação,

\footnotetext{
4 O processo de impeachment da Presidente Dilma Rousseff teve como objeto o desrespeito à Lei de Responsabilidade Fiscal ocasionado por meio das denominadas pedaladas fiscais e aprovação de medidas de obtenção de crédito suplementar.
} 
especialmente dos menos favorecidos, em prol de uma suposta racionalidade que entende que todos esses seres são os responsáveis pela emergência econômica e por isso devem ser castigados. Porém o que não é mencionado, e tão pouco discutido, é quem foram os mais beneficiados nos tempos de paz ou état de paix, para se valer do termo em francês.

O estado de exceção oriundo da emergência econômica pode afetar até mais direitos fundamentais do que o estado de sítio natural, ou ainda, em outras palavras, o rol de direitos fundamentais atingidos é ainda maior. Isso se deve porque não estaríamos falando apenas com relação à restrição de locomoção, reunião, associação, comunicação, mas de todo o rol de direitos que exigem por si só uma contraprestação por parte do Estado para que eles possam ser usufruídos, como os direitos sociais, e ainda outros direitos individuais, coletivos e difusos correlatos, a exemplo dos relacionados ao trabalho (podendo citar sobre essa questão a aposentadoria e previdência social, sindicalização e, terceirização devido as suas implicações tanto no âmbito individual como coletivo). Tomemos como exemplo a hipótese de corte em programas sociais: ao se reduzir as verbas destinadas a programas sociais, os quais buscam justamente a promoção dos direitos fundamentais, a renda destinada a essas atividades pode ser alocada para outras finalidades. Com relação a exemplo, não podemos também nos olvidar da aplicação do receituário ortodoxo imposto à Grécia e a outros países europeus que também foram amplamente afetados pela crise de 2008.

É notório que não podemos ser ingênuos e crer que o dinheiro surgirá para o Estado como num passe de mágica, mas seria realmente desejável que o Estado tivesse condições de oferecer os serviços da melhor maneira possível visando um estado de bem-estar social. Contudo, convêm deixar claro que problema da gestão financeira por parte do Estado não se resume exclusivamente a direitos fundamentais. Já nos ensina Schumpeter (1961), no capítulo 7 referente ao "processo de destruição criadora" em sua clássica obra "Capitalismo, Socialismo e Democracia”, que a base da concorrência no capitalismo está pautada no processo de constante inovação e, assim sendo, nos parece sensato afirmar que a educação, um direito fundamental, atua justamente no sentido de auxiliar no processo de inovação. São os ganhos oriundos da inovação que atuarão enquanto motor para o crescimento econômico.

Diante do exposto, entendemos que ainda que a emergência econômica não declare formalmente uma situação de estado de exceção de fato, ela o cria como sendo algo de fato. Dito isso, podemos não estar diante de um estado de exceção declarado, mas não é a mera ausência da declaração legal que faz com que o mesmo não se encontre plenamente instaurado e configurado. 
Partiremos agora para a próxima etapa de nossa reflexão, na qual analisaremos a influência do pensamento ortodoxo de modo a vermos como ela contribui para a retroalimentação, para a configuração do estado de exceção oriundo da emergência econômica.

\section{A INFLUÊNCIA DO PENSAMENTO ECONÔMICO ORTODOXO}

O pensamento ortodoxo fornece a base de sustentação da ideologia neoliberal e assim sendo, julgamos que é necessário entender, de maneira geral, o que fornece a estrutura que dá apoio à argumentação dessa escola de pensamento.

A vertente ortodoxa considera que a economia se ajusta por meio de um equilíbrio natural e sendo assim intervenções estatais são desnecessárias. A base estruturante do pensamento ortodoxo, conforme explica Sawaya (2015, p. 108) "se materializa na política de metas de inflação fundada no equilíbrio das 'taxas naturais' de emprego e produto, o que impede a intervenção pública sob o risco de quebrar a 'credibilidade' que compõe a natureza psicológica dos agentes". Portanto, “interferir nos mercados deixaria os agentes (trabalhadores, empresários e consumidores) confusos, sem saber se a variação nos preços é inflação ou sinal para ajustes necessários entre oferta e demanda" (SAWAYA, 2015, p. 110). Em outras palavras, o Estado seria uma espécie de vilão que, ao tocar no que não precisa ser tocado, atrapalha e arruína a economia. Assim, como o Estado não é necessário, as suas ações devem ser orientadas no sentido de permitir que a economia se ajuste naturalmente, e para isso é necessário que sejam promovidas a desregulamentação e a liberalização.

Além disso, a atual crise econômica, para os seguidores de tal vertente, seria em decorrência de que “os gastos públicos 'excessivos' (sociais) teriam subvertido a 'boa teoria' fundada nas 'leis da natureza' e assim retirado o 'mercado de trabalho' de seu 'equilíbrio natural' e o crescimento do PIB de seu 'potencial"” (SAWAYA, 2015, p. 106). Ainda com relação a atual crise econômica, complementa Sawaya (2015, p. 108), “o foco do momento passou a ser criticar a Constituição de 1988 que teria ampliado em demasia os direitos sociais em relação à capacidade de gasto do Estado. O objetivo é gerar superávits primários para pagar juros elevados e não gastos sociais”. Portanto, a explicação de Sawaya vai diretamente à nossa concepção de estado de exceção: temos a urgência de motivação econômica (a crise, e mais especificamente o "monstro inflacionário"), cuja solução para sair dela, de acordo com o receituário ortodoxo, é a supressão dos direitos fundamentais. Ironicamente porém, não 
podemos deixar passar, que "o monstro apareceu estranhamente após as políticas recessivas colocarem a economia de joelhos, e não antes"5 (SAWAYA, 2015, p. 106).

Cabe ainda lembrar que em 2014, conforme dados levantados por Maria Lucia Fattorelli e Rodrigo Ávila da associação Auditoria Cidadã da Dívida, considerando o total da dívida pública federal em relação ao orçamento (45,11\%, o que corresponde a 978 bilhões de reais), vemos a enorme discrepância que há com relação ao destinado à saúde $(3,98 \%$ do orçamento), educação $(3,73 \%)$, cultura $(0,04 \%)$, direitos da cidadania $(0,03 \%)$, transporte $(0,56 \%)$, ciência e tecnologia $(0,28 \%)$, etc, o que significa que a "sociedade não recebe os serviços sociais essenciais, como saúde e educação" e que "o país está com seu desenvolvimento socioeconômico travado, a serviço de garantir lucros escorchantes ao sistema financeiro" (FATTORELLI; ÁVILA, 2016). É claro que a dívida não surgiu do nada, mas nem por isso sua dimensão deixa de ser preocupante, pois isso significa que menos renda está sujeita a ser destinada aos serviços essenciais. Diante disso, podemos afirmar que o que temos são direitos fundamentais que estão ameaçados pelas finanças. Assim, a vertente ortodoxa neoliberal se torna ainda mais perversa pois ela não irá atacar o cerne do problema, mas irá retirar as verbas daquilo que já estava fragilizado para garantir que o Estado possa continuar a se endividar junto ao capital.

Retomando então o que vimos na seção anterior, os direitos sociais estão previstos no Capítulo II da Constituição (Dos Direitos Sociais), que abrange os artigos $6^{\circ}$ ao 11 . Disposto expressamente no art. $6^{\circ}$ temos a educação, saúde, alimentação, trabalho, moradia, transporte, lazer, segurança, previdência social, proteção à maternidade e à infância, assistência aos desamparados. No art $7^{\circ}$ têm-se os direitos dos trabalhadores urbanos e rurais, a exemplo da aposentadoria, alvo constante de críticas sobre a sua operacionalidade e de suas regras para obtenção do benefício. Já nos artigos $8^{\circ}$ ao 11 temos direitos atrelados ao direito coletivo do trabalho, como a livre associação profissional ou sindical (art. $8^{\circ}$ ), direito de greve (art. $9^{\mathrm{a}}$ ), representatividade de trabalhadores e empregadores em colegiados de órgãos públicos para representatividade em questões de interesse profissionais ou previdenciários (art. 10) e obrigatoriedade de representante dos trabalhadores para empresas com mais de 200 empregados (art. 11). Por fim, cabe observar que parte desses direitos se encontram regulamentados na própria Constituição, mais especificamente no Título VIII (Da Ordem Social), o qual aborda questões como saúde, previdência e trabalho.

\footnotetext{
${ }^{5}$ Alusão as políticas postas em práticas pelo então Ministro da Fazenda Joaquim Levy durante o governo Dilma.
} 
Temos então uma vertente aparentemente perigosa, a qual atua para "determinar com quem fica e quem se beneficia da renda nacional” (SAWAYA, 2015, p. 108), já que a renda nacional não seria mais destinada a universalizar todos os direitos previstos constitucionalmente, a exemplo dos supracitados. Nesse sentido, é possível afirmar que tal vertente basicamente rasga a nossa constituição como um mero pedaço de papel. É um retrocesso absoluto, uma ofensa direta não apenas ao constituinte, mas ao povo brasileiro: é uma negação às conquistas obtidas após um longo esforço histórico de positivação de direitos humanos, especialmente no pós-Segunda Guerra, e mesmo antes dela já que sempre é oportuno lembrar que a Organização Internacional do Trabalho (OIT) remonta a 1919 como parte do Tratado de Versalhes, o qual pôs fim à Primeira Guerra Mundial (OIT, 2016) sendo o Brasil um de seus países-membros. O que a vertente ortodoxa faz nos dias de hoje é reafirmar os ideais imperialistas do século XIX e início do século XX, subordinando especialmente os mais fracos, os mais dependentes das prestações do Estado que permitem viabilizar os direitos fundamentais, ao interesse do capital.

Qual seria então a base de apoio do pensamento econômico ortodoxo? O pensamento econômico ortodoxo remonta a sua origem aos autores clássicos, tais como Smith, Ricardo, Malthus, James Mill, McCulloch, Senir e John Stuart Mill. Nos primórdios do capitalismo, até parece razoavelmente sensata a vertente ortodoxa: naquela época a realidade social era outra e o capitalismo ainda dava seus primeiros passos em determinadas economias. Assim, sem grandes esforços, conforme explica Huberman (2013, p. 158), a teoria clássica desses autores citados ganharia adoção pelos homens de negócio da época porque se adequava as suas necessidades, já que delas podiam escolher as leis naturais que justificassem seus atos. Não obstante, vale mencionar que Smith e Ricardo são tidos como os pais do pensamento econômico liberal.

No entanto, Karl Marx, com sua obra "O Capital” e posteriormente, John Maynard Keynes, em sua “A Teoria Geral do Emprego, do Juro e da Moeda”, viriam romper com essa lógica dos clássicos.

Marx (2013), em sua obra "O Capital: crítica da economia política", critica os autores tidos como clássicos ora citados, especialmente Adam Smith e David Ricardo, pais do pensamento econômico liberal, do auto-ajuste ${ }^{6}$ de mercado, da mão-invisível. Assim, como é possível observar a partir de sua obra, a concepção de "leis naturais" de mercado é

\footnotetext{
${ }^{6} \mathrm{O}$ termo auto-ajuste também pode aparecer como auto-regulação dentro da literatura econômica.
} 
desmistificada. Marx demonstra como se dá a geração de riqueza nas economias capitalistas, bem como a geração de emprego, e isso não é pela via do auto-ajuste como abordado pelos clássicos ${ }^{7}$. Marx dá origem à denominada escola marxista.

Em sua obra "A Teoria Geral do Emprego do Juro e da Moeda", Keynes (1992) ${ }^{8}$ procura demonstrar que as economias capitalistas não possuem condições e capacidades para promover automaticamente o pleno emprego. Isso também rompe com a ideia típica de autoajuste de mercado, uma vez que, se há auto-ajuste automaticamente o mercado tender-se-ia ao pleno emprego. Por conta disso, caberia ao governo intervir diretamente, sendo ele então o agente responsável por fazer ajustes ao mercado. Hicks (1937), em seu artigo “Mr. Keynes and the classics: a suggested interpretation", a partir da interpretação da obra de Keynes, propõe o modelo IS-LM, o qual passa a introduzir a possibilidade de aplicação de política monetária e físcal como mecanismo de promoção de crescimento da renda a um determinado nível de juros, e com isso promover o pleno emprego ${ }^{9}$. Keynes dá origem às escolas keynesiana e pós-keynesianos.

No entanto, mesmo com a contribuição de Marx, Keynes e Hicks, as teorias clássicas seriam retomadas no pós-Segunda Guerra com o pensamento novo-clássico, o qual tem entre seus expoentes Muth (1961), Phelps (1967) e Friedman ${ }^{10}$ (1968), os quais nos interessa pois é a concepção deles que dá sustentáculo a concepção do pensamento ortodoxo dos dias de hoje.

Muth (1961) realiza uma abordagem que relaciona as expectativas racionais com a teoria de movimentação dos preços. Em outras palavras, ele aborda como os preços variam dadas as expectativas racionais dos agentes. Sua hipótese se baseia no fato de que na

\footnotetext{
${ }^{7}$ De modo a se evitar uma discussão ainda mais profunda e que fugiria do escopo desse artigo, mas ainda sim tendo em vista a questão do processo de construção do conhecimento, ao leitor que queira se aprofundar sobre essas questões provocadas, veja em Marx (2013) a abordagem sobre a extração da mais valia em suas formas absoluta e relativa como uma espécie de ponto de partida (já indicado anteriormente) e também a concepção sobre trabalho vivo e trabalho morto (relação entre lucro e trabalho).

${ }^{8}$ Cabe observar que a obra de Keynes (1992) teve em vista o fenômeno da Grande Depressão pós-queda da bolsa de Nova Iorque em 1929, a qual simboliza a falácia da mão-invisível já que se o ajuste de mercado promovido fosse perfeito tal crise jamais teria ocorrido.

${ }^{9}$ É oportuno ter em mente que pleno emprego, em termos econômicos, significa que em uma dada economia a maior parte dos agentes econômicos se encontra efetivamente empregada sendo que a outra parte compõe o denominado "exército de reserva" (agentes prontos para entrar no mercado quando necessário). Nesse sentido, em termos de direitos humanos, é fundamental que se busque o pleno emprego, isso é, a universalização das pessoas aos postos de trabalho, independentemente da posição de empregado ou empregador. Por sua vez, o trabalho é um elemento diretamente relacionado à dignidade da pessoa humana, já que dele o indivíduo obtém as condições materiais necessárias à sua subsistência. Por conta disso, é imperativo que o Estado busque fornecer às condições necessárias para a promoção e manutenção dos níveis de emprego.

${ }^{10}$ Naomi Klein (2008) em sua obra "A doutrina do choque", na segunda parte, demonstra a perversidade da doutrina neoliberal implantada nos países latino-americanos, dentro do contexto de ditaduras militares, como foi o caso da Argentina, Brasil e Chile e, ainda, o papel que teve Friedman e a escola de Chicago. Destaca-se ainda na obra a questão da supressão dos direitos fundamentais dentro dos regimes em estado de exceção.
} 
economia não se têm perda de informação, e que as expectativas dependem especificamente da estrutura do sistema como um todo. Segundo Luque (2011, p. 297), esse autor dá início à escola das expectativas racionais, também conhecida como novos-clássicos. Essa concepção de expectativas racionais "significava que os agentes econômicos, ao formarem suas expectativas sobre alguma variável econômica, acabariam por tentar verificar como aquela variável se comportava no tempo" (LUQUE, 2011, p. 297). Nessa linha de pensamento, afirma Luque (2011, p. 298), “os indivíduos sempre otimizariam, e os mercados sempre entrariam em equilíbrio". Em outras palavras, é um mundo perfeito por não haver variáveis que impedirão ou dificultarão o equilíbrio dos mercados.

Phelps (1967) e Friedman (1968), escreveram seus artigos inspirados na denominada "Curva de Phillips", a qual consiste em uma curva inversamente proporcional que relaciona o desemprego (valor em porcentagem) com a taxa de variação dos salários reais ${ }^{11}$ (valor em porcentagem), e que foi elaborada a partir da observação de dados do Reino Unido entre 1861-1957. Os autores "propõem que na equação explicativa das taxas de crescimento dos salários nominais deveríamos introduzir, além da taxa de desemprego, a taxa de inflação esperada" e, ao assim prosseguir, "passamos a ter um resultado completamente diferente porque, a cada taxa de inflação esperada, teremos uma determinada curva de Phillips" (LUQUE, 2011, p. 296). A consequência direta da crítica desses autores é que ela passa a admitir que são os trabalhadores que decidem quanto de emprego ofertam em razão de variações em seus salários reais e por isso há uma taxa natural de desemprego. Por sua vez, do lado das empresas, explica Sawaya $(2015$, p. 109) que elas não contratariam porque os salários elevados não compensariam a ampliação da produção. Nesse sentido, é possível observar nitidamente que essa lógica não está preocupada em garantir empregos com bons níveis salariais aos trabalhadores pois condiciona a contratação à redução salarial. Consequentemente a isso, também é possível afirmar que para eles pleno emprego não é uma preocupação já que esse "é um conceito concreto e definido, mesmo como um objetivo a ser alcançado: a menor taxa de desemprego possível no sentido de zero" (SAWAYA, 2015, p. 110).

Vemos então que a preocupação desses autores consiste em criar uma espécie de mundo próprio onde apenas o que interessa é a economia sendo ela regida por princípios

\footnotetext{
${ }^{11}$ No artigo de Phillips (1958), o termo original em inglês utilizado é rate of change of money wage rates. Recomendamos a leitura do mesmo aos leitores que queiram melhor compreender a abordagem de Phelps (1967) e Friedman (1968).
} 
microeconômicos. Essa característica faz com que o pensamento econômico ortodoxo esteja mais próximo de uma seita em termos ideológicos cujo Deus seria o mercado. Não interessa a vida das pessoas, mas sim que o mercado atinja o seu equilíbrio dado a sua lógica racional, e a fundamentação disso está em gráficos e demais instrumentos que permitam fornecer uma aparência científica.

Assim, podemos afirmar que a teoria ortodoxa admite que em determinadas situações, levando em consideração a racionalidade dos agentes, certos sacrifícios podem ser impostos à sociedade, não importando necessariamente o tempo que isso seja necessário, afinal, os mercados devem se ajustar naturalmente. E, mais ainda, por sacrifícios impostos devemos entender, especialmente, o afastamento dos direitos fundamentais, a exemplo dos direitos sociais. Em outras palavras, temos que o que se aceita é a submissão a um estado de exceção de motivação econômica na qual Direitos Fundamentais são afastados pela lógica de reprodução do Capital.

\section{ORTODOXIA ECONÔMICA: UMA AMEAÇA AOS DIREITOS FUNDAMENTAIS?}

Parece então sensato afirmar que essa vertente, a ortodoxa, é incompatível com o que se espera de um Estado Democrático de Direito, o qual deve atuar para todos e não apenas para uma classe de privilegiados (os detentores do capital). É uma vertente conveniente aos que estão no poder, o que aprofunda ainda mais as desigualdades. Apesar disso, o que se observa é que mesmo aqueles que seriam diretamente afetados pela perversidade dessa vertente parecem defendê-la. O discurso ortodoxo, mesmo aos mais leigos, é de fácil compreensão justamente por se pautar em leis naturais e tentar buscar sua fundamentação em instrumentos que aparentam possuir um aspecto científico. Tal como não se duvida da lei da gravidade de Newton, não se duvidaria da naturalidade da lei da oferta e da demanda. Isso é mais um reflexo da perversidade da ortodoxia, um efeito manipulador que força o indivíduo ao conformismo, ao não pensar que as coisas podem ser de outra forma: é assim e ponto final, não há o que fazer.

Por não se preocupar com as consequências do mundo real, a esfera não financeira, o pensamento econômico ortodoxo comete uma completa negação de todo um processo de construção histórica dos direitos fundamentais. 
Conforme aponta Chesnais (1996, p. 25) em seu clássico “A mundialização do capital":

[...] para os turiferários da globalização, a necessária adaptação pressupõe que a liberalização e a desregulamentação sejam levadas a cabo, que as empresas tenham absoluta liberdade de movimentos e que todos os campos da vida social, sem exceção, sejam submetidos à valorização do capital privado.

A desregulamentação e liberalização, promovida por meio do discurso político neoliberal durante os anos 80 , deu fomento a um novo ordenamento, popularmente conhecido como globalização (ou mundialização conforme os seguidores da escola francesa, a exemplo de Chesnais).

Se antes a regulamentação, promotora do pleno-emprego e do estado de bem-estar social, com suas benesses consolidadas por meio do Sistema Bretton Woods, serviu aos interesses dos detentores do capital que precisavam naquele período reconstruir e criar mercados devastados pela guerra (a exemplo da Europa e do Japão), agora esse ordenamento já não seria mais de serventia e o mesmo passa a se valer do conceito de taxas naturais de desemprego. $\mathrm{O}$ advento do Euromercado, a crise do petróleo, o choque dos juros promovidos por Paul Volcker, levariam a um frenesi nos mercados financeiros que resultaria na mudança de ritmo e direção do processo de reprodução social.

A tal da globalização criou uma acepção de estado de exceção por meio de suas ações de desregulamentação e liberalização. As normas que foram afastadas com o ideal neoliberal foram os direitos fundamentais, conquistados às duras penas ao longo da história, tendo necessitado de duas grandes guerras em um breve século XX, para serem reconhecidos pela sociedade internacional ${ }^{12}$. E agora, nesse momento, chegam ortodoxos neoclássicos que querem nos fazer crer por meio de seu discurso de racionalidade dos mercados de que é necessário reduzir e acabar com direitos, especialmente os trabalhistas (e aqui novamente destacamos a OIT, que surgiu em 1919, fruto direto da conquista e do reconhecimento dos esforços da classe trabalhadora) e demais direitos sociais ${ }^{13}$, para que os países possam

\footnotetext{
${ }^{12}$ Para não nos alongarmos ainda mais na discussão, fazemos aqui alusão à Carta das Nações Unidas de 1945 e à Declaração Universal dos Direitos Humanos de 1948, bem como demais instrumentos normativos correlatos que se seguiram. É oportuno ter em mente que a participação em tratados e conversões internacionais, apesar de, via de regra, ser facultativa, uma vez ratificada impõe aos Estados uma obrigação, que deve ser cumprida (princípio do pacta sunt servanda - "os pactos devem ser cumpridos"), e, consequentemente, ao se aplicar isso sobre os que versam sobre direitos humanos, os países que os ratificam devem atuar justamente no sentido de sua valorização. Assim, é certo afirmar que algo que até então se encontrava restrito no âmbito externo passa a gerar consequências no âmbito interno.

${ }^{13}$ Aos que queiram se aprofundar sobre essa questão sugerimos que veja na íntegra o artigo de Sawaya (2015) sobre a atual crise econômica e a ortodoxia.
} 
competir em maior igualdade no mercado internacional, ou seja, querem que os direitos passem a ser vistos como custos e assim serem eliminados para que possa extrair o máximo de valor possível, uma lógica de fácil compreensão, mas muito perigosa para o avanço da espécie humana já que coloca o homem meramente como instrumento de manipulação do Capital.

Portanto, nos parece certo afirmar que a ortodoxia econômica contribui não para a valorização dos direitos fundamentais, mas para a criação de um estado de exceção e, em decorrência disso, é uma ameaça aos direitos fundamentais. A emergência de caráter econômico passa a justificar a validade de toda e qualquer medida na antiga lógica maquiaveliana de os fins justificam os meios. É a sobreposição da razão de caráter humano pela razão econômica.

\section{CONSIDERAÇÕES FINAIS}

A atual crise política e econômica que o Brasil passa nesse ano de 2016, mas com suas raízes em períodos ainda anteriores, trouxe à tona a discussão sobre a ortodoxia econômica. Os operadores do direito se depararam com uma situação pouco discutida pois, inevitavelmente, tem a ver com os rumos que as políticas econômicas governamentais devem ser exercidas. Conforme abordado, os motivos da crise econômica, segundo a grande mídia, teriam como principal argumento a intervenção do Estado na economia, de violar não apenas as leis universais de auto-regulação, mas principalmente o ato de realizar gastos tidos como desnecessários: os direitos fundamentais e, em especial, os direitos sociais.

Ao se buscar incentivar a liberalização e a desregulamentação o que se está promovendo em termos práticos é uma acepção de estado de exceção que consequentemente suprime os direitos fundamentais. Nesse caso, é declarada uma espécie de estado de emergência econômico em que vale tudo para recuperar o estado de normalidade da economia, incluindo o enfraquecimento do aparato estatal e a condenação de sua população à miséria e à pobreza. Esse fenômeno de estado de exceção enfraquece as democracias a partir das supressões dos direitos adquiridos, independentemente do país se localizar no centro ou na periferia do capitalismo.

Direito e economia não podem ser vistos como dois universos distintos. Os reflexos de um implicam diretamente no outro. Nesse sentido, é necessário que se busque um ponto de equilíbrio visando a garantia, manutenção e ampliação dos direitos fundamentais concomitantemente à ordem econômica. Em outras palavras, é preciso buscar um capitalismo humanista, que visa a inclusão e não a exclusão dos indivíduos de seu ordenamento. Obviamente que buscar tal equilíbrio não é algo fácil, e 
ainda que seja atingido o mesmo ainda estará sujeito a intempéries que podem levá-lo à derrocada, tal como ocorreu com o Sistema Bretton Woods. No entanto, um primeiro passo deve ser dado, e essa é a reflexão em âmbito acadêmico.

\section{REFERÊNCIAS BIBLIOGRÁFICAS}

AGAMBEN, G. Estado de exceção. Trad. Iraci D. Poleti. 2. Ed. São Paulo: Boitempo, 2004

ALEMANHA. Verordnung des Reichspräsidenten zum Schutz von Volk und Staat. 28 de fevereiro de 1933. Suprime dispositivos da Constituição de Weimar. Disponível em: http://www.documentarchiv.de/ns/rtbrand.html . Acesso em: 14. Jul. 2016.

BRASIL. Constituição (1988). Constituição da República Federativa do Brasil. Brasília, DF: Senado, 1988. Disponível em http://www.planalto.gov.br/ccivil_03/Constituicao/Constituicao.htm . Acesso em 14. Jul. 2016.

BORON, A. A Coruja de Minerva: mercado contra democracia no capitalismo contemporâneo. Trad. Ana Carla Ferreira. Petrópolis: Vozes, 2001.

CHESNAIS, F. A mundialização do capital. São Paulo: Xamã, 1996.

FATTORELli, M. L; ÁVILA, R. Gastos com a dívida pública em 2014 superaram $45 \%$ do orçamento federal executado. Disponível em: http://www.auditoriacidada.org.br/blog/2015/02/24/gastos-com-a-divida-publica-em-2014-superaram45-do-orcamento-federal-executado/ . Acesso em: 14. Jul. 2016.

FLORES, J. H. Teoria Crítica dos Direitos Humanos. Trad. Luciana Caplan. Rio de Janeiro: Ed. Lumen Juris Ltda, 2009.

FRIEDMAN, M. The role of monetary policy. The American Economic Review, v. 58, n. 1, p. 1-17. Mar. 1968

HICKS, J. R. Mr Keynes and the Classics; a suggested interpretation. Econometrica, v. 5, n. 2, p. 147-159. Abr. 1947

HUBERMAN, L. História da Riqueza do Homem. Tradução de Walternsir Dutra; Atualização e revisão técnica de Marcia Guerra. 22. Ed. Rio de Janeiro: LTC, 2013.

KEYNES, J. M. A Teoria Geral do Emprego, do Juro e da Moeda. Tradução de Mário R. da Cruz; Revisão técnica de Cláudio Roberto Contador. São Paulo: Atlas, 1992. 
KLEIN, N. The Shock Doctrine: The Rise of Disaster Capitalism. Londres (Inglaterra): Picador, 2008.

LUQUE, C. A. Teoria macroeconômica: evolução e situação atual. In: PINHO, D. B; VASCONCELlOS, M. A. S.; TONETO JÚNIOR, R. Manual de economia. 6. Ed. São Paulo: Editora Saraiva, 2011.

MARX, K. O capital: crítica da economia política: Livro 1: o processo de produção do capital. Tradução Rubens Enderle. São Paulo: Boitempo, 2013.

MUTH, J. F. Rational expectations and the theory of price movements. Econometrica, v. 29, n. 3, p. 315-335. Jul. 1961

OIT. História. Disponível em: < http://www.oitbrasil.org.br/content/hist\%C3\%B3ria . Acesso em: 14. Jul. 2016.

PAULANI, L. M. Capitalismo financeiro e estado de emergência econômico no Brasil: o abandono da perspectiva do desenvolvimento. In: X Jornada de Economia Crítica, 23 a 25 de março de 2006, Barcelona, 2006. Disponível em: http://www.ucm.es/info/ec/jec10/ponencias/713Paulani.pdf . Acesso em: 10 Jul. 2016.

PHELPS, E. S. Phillips Curves, Expectations of Inflation and Optimum Unemployment Over Time. Economica, v. 34, n. 135, p. 254-281. Ago. 1967

PHILLIPS, A. W. The relation between unemployment and the rate of change of Money wage rates in U.K. 1861-1957. Economica, v. 25, n. 100, p. 283-299. Nov. 1958

SAWAYA, R. R. Poder, emprego e política econômica. Estudos Avançados [online]. São Paulo (SP), v. 29, n. $85, \quad$ p. 105-119, Dez. 2015. Disponível em http://www.scielo.br/scielo.php?script=sci_arttext\&pid=S0103-

40142015000300008\&lng=en\&nrm=iso . Acesso em: 18 Abr. 2016. http://dx.doi.org/10.1590/S010340142015008500008 .

SCHUMPETER, J. Capitalismo, Socialismo e Democracia. Rio de Janeiro: Editora Fundo de Cultura, 1961. 